\title{
A systematic review of overall survival in pediatric primary glioblastoma multiforme of the spinal cord
}

\author{
Subhas K. Konar, MCh, Shyamal C. Bir, MD, PhD, Tanmoy K. Maiti, MD, MCh, and \\ Anil Nanda, MD, MPH \\ Department of Neurosurgery, LSU Health Shreveport, Louisiana
}

\begin{abstract}
OBJECTIVE The incidence of primary spinal cord glioblastoma multiforme (GBM) in the pediatric age group is very rare. Only a few case series and case reports have been published in the literature; therefore, overall survival (OS) outcome and the as-yet poorly defined management options are not discussed in detail. The authors performed a cumulative survival analysis of all reported cases of pediatric spinal cord GBM to identify the predictive factors related to final survival outcome.

METHODS A comprehensive search for relevant articles was performed on PubMed's electronic database MEDLINE for the period from 1950 to 2015 using the search words "malignant spinal cord tumor" and "spinal glioblastoma multiforme." This study was limited to patients younger than 18 years of age. Survival rates for children with various tumor locations and treatments were collected from the published articles and analyzed.
\end{abstract}

RESULTS After an extensive literature search, 29 articles met the study inclusion criteria. From the detailed information in these articles, the authors found 53 children eligible for the survival analysis. The majority (45\%) of the children were more than 12 years old. Thirty-four percent of the cases were between 7 and 12 years of age, and $21 \%$ were younger than 7 years. In the Kaplan-Meier survival analysis, children younger than 7 years of age had better survival (13 months) than the children older than 7 years (7-12 years: 10 months, $>12$ years: 9 months; $p=0.01$, log-rank test). Fifty-five percent of the children were female and $45 \%$ were male. A cervical tumor location (32\%) was the most common, followed by thoracic $(28.3 \%)$. Cervicothoracic (18.9\%) and conus (18.8\%) tumor locations shared the same percentage of cases. Cervical tumors had a worse outcome than tumors in other locations ( $p=0.003$, log-rank test). The most common presenting symptom was limb weakness (53\%), followed by sensory disturbances (25\%). Median OS was 10 months. The addition of adjuvant therapy (radiotherapy [RT] and/or chemotherapy [CT]) after surgery significantly improved OS ( $p=$ 0.01 , log-rank test). Children who underwent gross-total resection and RT had better outcomes than those who underwent subtotal resection and RT ( $p=0.04$, log-rank test). Cerebrospinal fluid spread, hydrocephalus, brain metastasis, and spinal metastasis were not correlated with OS in primary spinal GBM.

CONCLUSIONS Adjuvant therapy after surgery had a beneficial effect on overall outcome of spinal GBM in the pediatric age group. Gross-total resection followed by RT produced a better outcome than subtotal resection with RT. Further large-scale prospective study is required to establish the genetic and molecular factors related to OS in primary GBM of the spinal cord in pediatric patients.

http://thejns.org/doi/abs/10.3171/2016.8.PEDS1631

KEY WORDS children; spinal glioblastoma; survival outcome; spine; oncology

A MONG all pediatric tumors in the central nervous system, the incidence of intramedullary spinal cord tumors is less than one-third of $1 \%$, and of these only $1 \%-3 \%$ are high-grade spinal tumors. ${ }^{25}$ Pediatric glioblastoma multiforme (GBM) differs from adult
GBM in tumor etiology. Pediatric infratentorial GBMs show a molecular karyotype that is more characteristic of pediatric embryonal tumors than adult GBM..$^{49}$ Overall survival (OS) and the management protocol in pediatric GBM also differ from those in adult GBM. Few studies

ABBREVIATIONS CSF = cerebrospinal fluid; CT = chemotherapy; GBM = glioblastoma multiforme; GTR = gross-total resection; HGG = high-grade glioma; NOS = not otherwise specified; OS = overall survival; $\mathrm{RT}=$ radiotherapy; $\mathrm{STR}=$ subtotal resection.

SUBMITTED January 15, 2016. ACCEPTED August 4, 2016.

INCLUDE WHEN CITING Published online November 4, 2016; DOI: 10.3171/2016.8.PEDS1631. 
have been published on the management of and survival outcome in pediatric intracranial GBM ${ }^{38}$ Rarer still is the pediatric primary spinal cord GBM. Hence, treatment protocol and OS are difficult to assess in this group of children. Ononiwu et al. ${ }^{38}$ in a study of 8 children with a diagnosis of pediatric spinal cord GBM, reported a median survival of 15 months. In another study, Lober et al. ${ }^{25}$ wrote about 2 patients with primary pediatric spinal cord GBM, citing an average OS of 14 months. The beneficial role of safe resection and radiotherapy (RT) in intracranial GBM is confirmed in the literature..$^{30}$ Neurosurgeons and pediatric oncologists must determine if the same principle can be applied in spinal GBM. In this context, our aim was to perform integrative survival analysis by extracting each case from the literature and investigating more precisely the degree of association between the various predictive factors and OS by using Kaplan-Meier analysis.

\section{Methods}

\section{Search Strategy}

We followed the Preferred Reporting Items for Systematic Reviews and Meta-Analyses (PRISMA) guidelines for this study. A search on PubMed's electronic database MEDLINE was performed using standard strings such as "malignant spinal cord tumor" and "spinal glioblastoma multiforme" as well as medical subject headings. The particular search strings used in the PubMed search builder and the number of article titles generated by strings are summarized in Fig. 1 and Table 1.,2,5,8-10, 13,17-21,25,27-29,31,32,36,38,42-44,46,48,51,54,56,60 To determine which articles to include, 2 separate reviewers (neurosurgeons) read and screened all titles. The abstracts of selected papers were screened, and data were extracted from those papers after matching the inclusion criteria. After scrutinizing the text of the articles and eliminating duplications, 29 articles were chosen for the final analysis. NonEnglish language papers were included for analysis only if an English language abstract was available. The availability of individual patient information as regards demographics (age at presentation, sex), spinal tumor location, critical events (death), time to events, and treatment characteristics (extent of resection, RT with or without chemotherapy [CT]) was an important inclusion criterion. A case report reporting on an isolated child younger than 18 years was included for analysis, but articles that reported aggregated data were excluded. Similar studies done in the same place were not included in our analysis to exclude the duplicate patients. Reports from the same institution in different time frames were included after careful examination.

\section{Data Extraction}

Demographic features (age, sex), location of tumor, extent of resection, use of adjuvant treatment (RT and/ or CT), disease recurrence, OS, and time to recurrence or death were extracted from the included articles. Age was categorized into 3 groups to correlate the impact of age on OS: younger than 7 years, 7-12 years, and older than 12 years. ${ }^{22}$ Tumors were grouped according to loca-
Search strings generated

$\mathrm{N}=560$

Titles screened, papers rejected on the basis of titles $\mathrm{N}=327$<smiles>CCCCCC</smiles>

Selected for abstract reading

$\mathrm{N}=233$<smiles>C1C2CC3CC1CC(C2)C3</smiles>

Papers selected for reading full text

$\mathrm{N}=71$

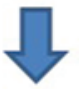

\section{Papers finally selected after deleting duplicates, pediatric cases \\ $\mathrm{N}=29$}

FIG. 1. Literature search criteria in the selection of articles. Figure is available in color online only.

tion: cervical, cervicothoracic, thoracic, conus, and others (holocord, unspecified). Gross-total resection (GTR), subtotal resection (STR), biopsy, and not otherwise specified (NOS) were the subgroups based on extent of resection. Primary treatment had 4 categories: surgery alone, surgery plus RT, surgery plus CT, and surgery plus RT and CT. Available data on cerebrospinal fluid (CSF) dissemination, hydrocephalus, and brain metastasis were extracted and used to assess OS. The OS (death) was documented from respective articles.

\section{Statistical Analysis}

Survival outcome was analyzed with the Kaplan-Meier estimator, and comparison was performed using the log-rank test. For univariate analysis, the Cox regression model was used to demonstrate the impact of individual predictive factors on OS outcome. Hazard ratios with $95 \%$ confidence intervals were calculated. The Cox multivariate regression model was applied to assess the interrelationship among the predictive factors and the final outcome. Analyses were performed utilizing SPSS software (version 21, IBM Corp.). A p $<0.05$ was considered statistically significant.

\section{Results}

\section{Patients and Tumor Characteristics}

Fifty-three children matching inclusion criteria were subjects in the final analysis (Table 2). The mean age at presentation was 10 years. The majority of children were more than 12 years old (45\%), followed by those who were $7-12$ years (34\%) and those younger than 7 years (21\%). In 
TABLE 1. Review of the literature on primary spinal GBM in pediatric patients

\begin{tabular}{|c|c|c|c|c|c|c|c|}
\hline Case No. & Authors \& Year & Age (yrs)/Sex & Level of Tumor & Surgery & RT & CT & Survival (mos) \\
\hline 1 & Das et al., 2012 & $9 / F$ & Thoracic & NR & Y & Y & 8 \\
\hline 2 & Narayana et al., 2010 & $14 / \mathrm{M}$ & C2-7 & STR & $\mathrm{N}$ & $\mathrm{N}$ & 2 \\
\hline 3 & Finlay et al., 1995 & $9 / F$ & Conus & STR & $\mathrm{Y}$ & $Y$ & 10 \\
\hline 4 & Perkins et al., 2011 & $15 / F$ & C6-7 & STR & $\mathrm{Y}$ & $Y$ & 6 \\
\hline 5 & O'Halloran et al., 2013 & $10 / F$ & Cervicothoracic & STR & $Y$ & $Y$ & 12 \\
\hline 6 & & $10 / F$ & Cervical & GTR & $\mathrm{Y}$ & $Y$ & 14 \\
\hline 7 & & $12 / \mathrm{M}$ & Cervical & GTR & $\mathrm{Y}$ & $Y$ & 14 \\
\hline 8 & & $2 / \mathrm{M}$ & Thoracic & GTR & Y & Y & 30 \\
\hline 9 & & $17 / F$ & Thoracic & Biopsy & Y & Y & 11 \\
\hline 10 & & $14 / F$ & Thoracic & STR & $\mathrm{Y}$ & Y & 15 \\
\hline 11 & & $4 / F$ & Cervical & STR & $Y$ & Y & 10 \\
\hline 12 & Merchant et al., 1999 & $10 / F$ & Conus & Biopsy & $\mathrm{Y}$ & $Y$ & 14 \\
\hline 13 & Kawashima et al., 2004 & $16 / F$ & Thoracolumbar & Biopsy & Y & Y & 12 \\
\hline 14 & Lam et al., 2012 & $14 / F$ & C6-T5 & GTR & Y & Y & 10 \\
\hline 15 & & $8 / F$ & C3-T4 & STR & Y & Y & 14 \\
\hline 16 & Strik et al., 2000 & $14 / \mathrm{M}$ & Conus & STR & NR & NR & 16 \\
\hline 17 & Banczerowski et al., 2003 & $16 / \mathrm{M}$ & Conus & GTR & Y & $\mathrm{N}$ & 6 \\
\hline 18 & Lober et al., 2010 & $16 / \mathrm{M}$ & Cervicothoracic & STR & Y & Y & 6 \\
\hline 19 & & $8 / F$ & Thoracolumbar & STR & Y & Y & 10 \\
\hline 20 & & $8 / \mathrm{M}$ & Cervical & STR & Y & $\mathrm{N}$ & 4 \\
\hline 21 & & $11 / \mathrm{M}$ & Cervicothoracic & STR & Y & Y & 17 \\
\hline 22 & Sharma et al., 2010 & $14 / \mathrm{M}$ & Conus & STR & Y & $\mathrm{N}$ & 10 \\
\hline 23 & Campbell et al., 1996 & $6 / \mathrm{M}$ & Thoracic & STR & Y & Y & 9 \\
\hline 24 & Prasad et al., 2012 & $10 / F$ & Cervical & Biopsy & $\mathrm{N}$ & $\mathrm{N}$ & 3 \\
\hline 25 & Massimino et al., 2005 & $14 / \mathrm{M}$ & Conus & STR & Y & $\mathrm{N}$ & 11 \\
\hline 26 & Ansari et al., 2012 & $12 / F$ & Cervical & STR & Y & $\mathrm{N}$ & 6 \\
\hline 27 & & $14 / F$ & Conus & STR & $\mathrm{N}$ & Y & 11 \\
\hline 28 & Russell \& Rubinstein, 1959 & $18 / F$ & $\mathrm{C} 7-\mathrm{T7}$ & GTR & Y & NR & 21 \\
\hline 29 & & $3 / M$ & $\mathrm{~T}-7$ & Biopsy & Y & Y & 13 \\
\hline 30 & & $14 / \mathrm{M}$ & C2-7 & STR & Y & Y & 9 \\
\hline 31 & & $18 / F$ & Cervicothoracic & GTR & Y & $\mathrm{N}$ & 21 \\
\hline 32 & & $18 / F$ & Cervicothoracic & GTR & $\mathrm{Y}$ & $\mathrm{N}$ & 21 \\
\hline 33 & & $18 / F$ & Cervicothoracic & GTR & Y & $\mathrm{N}$ & 21 \\
\hline 34 & Johnson \& Schwarz, 1987 & $8 / F$ & Cervical & STR & Y & Y & 1 \\
\hline 35 & Kim et al., 2011 & 12 & $\mathrm{C} 1-7$ & STR & $\mathrm{N}$ & $\mathrm{N}$ & 2 \\
\hline 36 & McGirt et al., 2008 & $2 / F$ & C7-T7 & GTR & Y & $\mathrm{N}$ & 14 \\
\hline 37 & & $1 / \mathrm{M}$ & $\mathrm{C} 7-\mathrm{T} 2$ & STR & Y & Y & 13 \\
\hline 38 & & $1 / \mathrm{M}$ & $\mathrm{C} 3-\mathrm{T} 7$ & Biopsy & Y & Y & 24 \\
\hline 39 & Adams et al., 2016 & $4 / M$ & Holocord & STR & $\mathrm{N}$ & Y & 37 \\
\hline 40 & & $13 / F$ & Cervical & GTR & Y & $Y$ & 15 \\
\hline 41 & & $15 / M$ & Cervical & STR & $\mathrm{N}$ & Y & 8 \\
\hline 42 & Pollack et al., 2006 & $18 / \mathrm{M}$ & T9-L1 & STR & $\mathrm{N}$ & $\mathrm{N}$ & 3 \\
\hline 43 & Caroli et al., 2005 & $10 / F$ & C2-7 & STR & Y & $\mathrm{N}$ & 3 \\
\hline 44 & Ciappetta et al., 1991 & $16 / F$ & Conus & NR & Y & NR & 6 \\
\hline 45 & & $14 / \mathrm{M}$ & Conus & NR & Y & NR & 4 \\
\hline 46 & & $17 / F$ & Thoracic & NR & NR & NR & 10 \\
\hline 47 & Wisoff et al., 1998 & $1 / F$ & $\mathrm{C} 1-\mathrm{T} 2$ & NR & Y & $\mathrm{N}$ & 64 \\
\hline 48 & & $13 / \mathrm{M}$ & T9-12 & STR & Y & $\mathrm{N}$ & 1 \\
\hline
\end{tabular}


» CONTINUED FROM PAGE 241

TABLE 1. Review of the literature on primary spinal GBM in pediatric patients

\begin{tabular}{|c|c|c|c|c|c|c|c|}
\hline Case No. & Authors \& Year & Age (yrs)/Sex & Level of Tumor & Surgery & RT & CT & Survival (mos) \\
\hline 49 & Gee et al., 2012 & $9 / F$ & Thoracolumbar & NR & Y & $\mathrm{N}$ & 14 \\
\hline 50 & Sun et al., 2009 & $12 / F$ & Conus & NR & NR & NR & 11 \\
\hline 51 & Minehan et al., 2009 & $18 / F$ & Cervical & STR & Y & $\mathrm{N}$ & 4 \\
\hline 52 & & $1 / \mathrm{M}$ & Cervical & STR & $\mathrm{N}$ & $\mathrm{N}$ & $10^{*}$ \\
\hline 53 & Raco et al., 2005 & $11 / \mathrm{F}$ & Cervical & NR & $\mathrm{N}$ & $\mathrm{N}$ & 6 \\
\hline
\end{tabular}

the Kaplan-Meier survival analysis, children younger than 7 years of age had better survival (13 months) than those who were older than 7 years ( $7-12$ years: 10 months, $>12$ years: 9 months, $p=0.01$, log-rank test; Fig. 2). Forty-five percent of the children were male and $55 \%$ were female. Patient sex did not influence OS. The most common presenting symptom was limb weakness (53\%), followed by sensory disturbances (24\%), back pain (21\%), and bladder and bowel disturbances (17\%). Median OS was 10 months. The 6-month survival rate was $67 \%$, the 12 -month rate was $35 \%$, and the 18 -month rate was only $9 \%$. Thirtytwo percent of the tumors were cervical and $28.3 \%$ were thoracic; $18.9 \%$ were cervicothoracic and $18.9 \%$ were at a conus location (Fig. 3). A cervical location (6 months' survival) had the worst outcome in comparison with thoracic (12 months), cervicothoracic (13 months), and conus (10 months; $p=0.003, \log$-rank test).

Univariate analysis (Table 3) also showed that a cervicothoracic location was associated with both 12-month mortality (HR $0.30,95 \%$ CI $0.09-0.99, \mathrm{p}=0.048$ ) and 18 -month mortality (HR 0.37, 95\% CI 0.15-0.91, $\mathrm{p}=0.03$ ). Even the Cox multivariate hazard model analysis showed a strong correlation between a cervicothoracic tumor location and OS (HR 0.24, 95\% CI 0.09-0.62, p = 0.004; Table 4). Thoracic (HR $0.27,95 \%$ CI $0.10-0.72, \mathrm{p}=0.009$ ) and conus (HR $0.19,95 \%$ CI $0.06-0.56, \mathrm{p}=0.003$ ) locations had an influence on OS as well. Cerebrospinal fluid spread was noted in $42 \%$ of the patients, and the median OS in those with CSF dissemination was 10 months. There was no significant difference in OS in the patients with or without CSF dissemination ( $\mathrm{p}=0.30$, log-rank test; Fig. 4). Hydrocephalus was noted in $13.2 \%$ of patients with 8 months of median survival. The local recurrence rate was $15 \%$. Brain metastasis was noted in $22.6 \%$ of the patients with 9 months' median survival. Overall spinal metastasis was noted in $9.4 \%$ of the children with a median survival of 11 months.

\section{Extent of Surgery}

Subtotal resection was performed in $54.7 \%$ of the cases, and GTR was achieved in 17\% (Fig. 5). Biopsy was done in $13.2 \%$ of the cases. Extent of resection was not related to mortality at 6,12 , or 18 months (Table 3 ). However, in the Cox multivariate hazard model analysis (Table 4), GTR (HR $0.23,95 \%$ CI $0.07-0.77, \mathrm{p}=0.01$ ) had a significant association with OS. The OS after GTR was 14 months in comparison with 9 months for STR.

\section{Surgery Alone Versus Surgery With Adjuvant Therapy}

Seventeen percent of the children underwent surgery only. Forty-nine percent received both RT and CT after surgery, $28.3 \%$ received only RT after surgery, and 6\% received only CT after surgery. Gross-total resection with RT had a better outcome than STR with radiation $(\mathrm{p}=$ 0.04, log-rank test; Fig. 6). Patients who received adjuvant therapy had a better median survival than those who had surgery alone, as shown in the Kaplan-Meier analysis ( $\mathrm{p}$ $=0.01, \log$-rank test; Fig. 7). In both univariate and multivariate analyses, the addition of RT and/or CT did not have an association with 6,12 , or 18 months' mortality. Prognosis was the worst in those children who underwent STR without adjuvant therapy (9 months).

\section{Discussion}

The management protocol for malignant spinal cord glioma in children is controversial, and clear guidelines are not available to neurosurgeons or oncologists. Knowledge about the survival outcome of a child harboring a malignant spinal cord tumor is essential for a physician to guide caregivers about future treatment. The prognosis of primary spinal GBM, in comparison to intracranial GBM, is not clear despite advances in neuroimaging, microsurgical technique, and oncological therapy. Therefore, we performed a comprehensive literature search to determine all factors predictive of survival in GBM of the spinal cord.

Wolff et al. ${ }^{59}$ reported that an age less than 5 years was related to a superior outcome in malignant spinal cord tumor. In a population-based study, Lam et al. ${ }^{23}$ found that an age group 13-18 years old had worse survival than other age groups and that patient sex did not affect OS. In our analysis, we found that the survival rate was better in patients with an age less than 7 years. In intracranial GBM, the mean age at presentation was $8.8-13$ years in the literature..$^{35,47}$ The present study showed the mean age at presentation for primary spinal GBM was $10 \pm 5.1$ years. For intracranial GBM, studies have shown a male predominance. In the present study, however, we found a male/female ratio of 1:1.2; therefore, patient sex did not appear to have any influence on overall outcome.

In a retrospective study, ${ }^{38}$ a child with thoracic tumor (18.7 months) had better OS than a child with cervical (12.5 months) or cervicothoracic (11.5 months) tumors. In another study, ${ }^{45}$ it was evident that patients with tumors lo- 
TABLE 2. Demographic and treatment characteristic of 53 pediatric patients with primary spinal GBM

\begin{tabular}{|c|c|c|c|}
\hline Variable & $\begin{array}{c}\text { No. of } \\
\text { Patients (\%) }\end{array}$ & $\begin{array}{l}\text { Information Available } \\
\text { for Analysis }\end{array}$ & $\begin{array}{l}\text { OS } \\
\text { (mos) }\end{array}$ \\
\hline \multicolumn{4}{|l|}{ Age } \\
\hline$<7 \mathrm{yrs}$ & $11(20.7)$ & $100 \%$ & 13 \\
\hline $7-12$ yrs & $18(34)$ & & 10 \\
\hline$>12$ yrs & $24(45.3)$ & & 9 \\
\hline \multicolumn{4}{|l|}{ Sex } \\
\hline Male & $24(45.3)$ & $98 \%$ & 9 \\
\hline Female & $29(54.7)$ & & 10 \\
\hline Tumor location & & $100 \%$ & \\
\hline Cervical & $17(32)$ & & 6 \\
\hline Cervicothoracic & $10(18.9)$ & & 13 \\
\hline Thoracic & $15(28.3)$ & & 12 \\
\hline Conus & $10(18.9)$ & & 10 \\
\hline NOS & $1(1.9)$ & & 37 \\
\hline \multicolumn{4}{|l|}{ Symptoms } \\
\hline Back pain & $11(21)$ & $55 \%$ & \\
\hline Sensory involvement & $13(24)$ & $56.6 \%$ & \\
\hline Extremity weakness & $28(53)$ & $56.6 \%$ & \\
\hline $\begin{array}{r}\text { Bladder/bowel } \\
\text { disturbance }\end{array}$ & $9(17)$ & $56.6 \%$ & \\
\hline Surgery type & & $100 \%$ & \\
\hline Biopsy & 7 (13.2) & & 13 \\
\hline STR & $29(54.7)$ & & 9 \\
\hline GTR & $9(17)$ & & 14 \\
\hline NOS & $8(15)$ & & 8 \\
\hline Treatment type & & $100 \%$ & \\
\hline Surgery & $9(17)$ & & 3 \\
\hline Surgery+RT & $15(28.3)$ & & 6 \\
\hline Surgery+CT & $3(6)$ & & 10 \\
\hline Surgery+RT+CT & $26(49)$ & & 11 \\
\hline CSF dissemination & $22(41.5)$ & $32 / 53$ & 10 \\
\hline Brain metastases & $12(22.6)$ & $16 / 53$ & 9 \\
\hline Spine metastases & $5(9.4)$ & $7 / 53$ & 11 \\
\hline Recurrence & $8(15)$ & $19 / 53$ & 13 \\
\hline Hydrocephalus & 7 (13.2) & $24 / 53$ & 8 \\
\hline
\end{tabular}

cated in the cervical region had poorer survival than those with a thoracic tumor location. In the present comprehensive analysis, we also showed that cervical (6 months) tumors had the worst outcome in comparison with thoracic (12 months) and cervicothoracic (13 months) locations (p $=0.003$, log-rank test). This finding may be attributable to tumor infiltration of the high cervical cord and instability of the cervical spine after surgery. ${ }^{45}$

Because of recent advances in microneurosurgical techniques, extent of resection has a major role in determining OS in malignant spinal cord tumors. Ononiwu et al. ${ }^{38}$ noted a mean survival of 19.2 months in children who underwent GTR as compared with 12.6 months in those who underwent STR. Wolff et al. ${ }^{59}$ reported that extent of

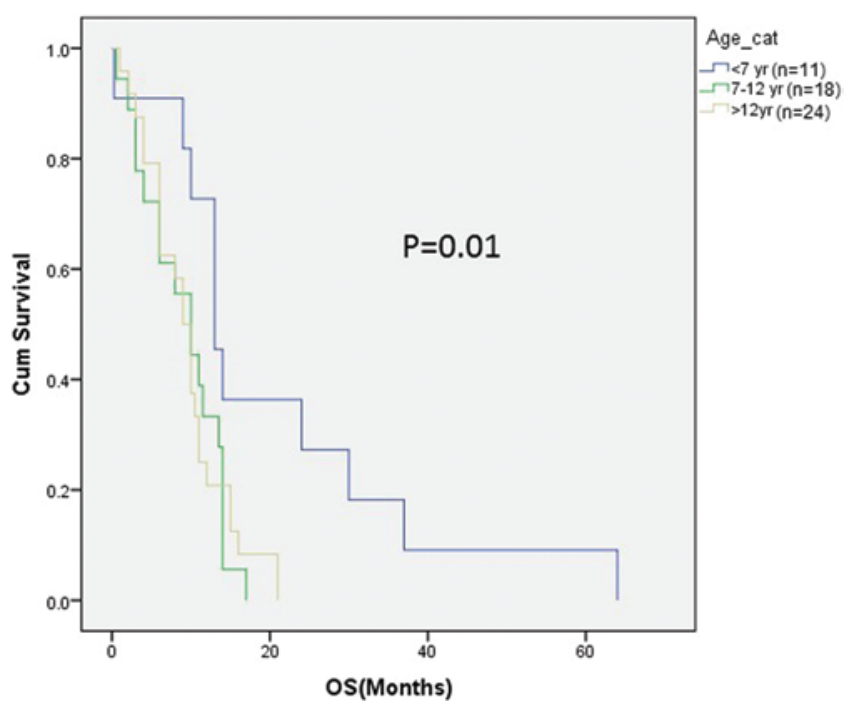

FIG. 2. Comparison of OS based on age $(<7,7-12$, and $>12$ years) in children with primary spinal GBM. A $p<0.05$ was considered statistically significant. cat $=$ category; Cum $=$ cumulative. Figure is available in color online only.

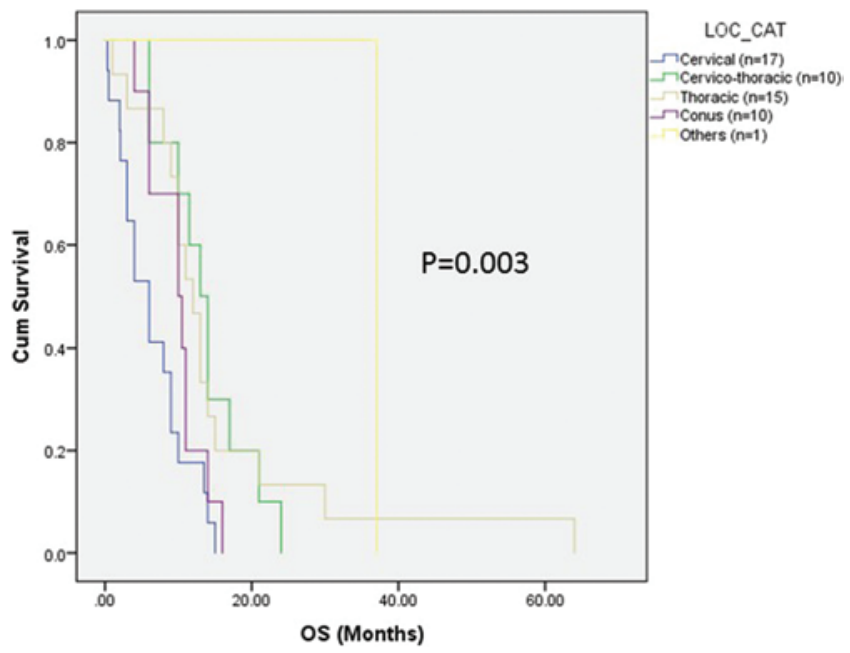

FIG. 3. Comparison of OS based on tumor location (LOC) in the spinal cord. A $p<0.05$ was considered statistically significant. Figure is available in color online only.

resection was related to OS in spinal GBM. However, Lam et al. ${ }^{1}$ published a conflicting report indicating that extent of resection is not related to OS in spinal GBM.

Extent of resection does play a role in the OS of children with intracranial GBM. ${ }^{17,12,22,40,58}$ In pediatric intracranial GBM, the mean survival time of children with GTR was 73.5 months $(p=0.030)$ compared with 13 months in children with STR, as reported by Nikitovic et al. ${ }^{35}$ Children with GBM treated using GTR had a 5-year progressionfree survival of $26 \%$ compared with $4 \%$ for those with an STR $(\mathrm{p}=0.046) .{ }^{58}$

In our study, we found that extent of resection does not have a direct relationship with OS. However, GTR plus RT had a more positive impact on OS than STR plus RT ( $p=$ 
TABLE 3. Univariate analyses of risk factors for mortality in 53 patients

\begin{tabular}{|c|c|c|c|c|c|c|c|c|c|c|c|c|}
\hline \multirow[b]{3}{*}{ Variable } & \multicolumn{4}{|c|}{6 Mos* $^{*}$} & \multicolumn{4}{|c|}{12 Mos† } & \multicolumn{4}{|c|}{18 Mosł } \\
\hline & \multirow[b]{2}{*}{$\mathrm{HR}$} & \multicolumn{2}{|c|}{$95 \% \mathrm{Cl}$} & \multirow{2}{*}{$\begin{array}{c}p \\
\text { Value }\end{array}$} & \multirow[b]{2}{*}{$\mathrm{HR}$} & \multicolumn{2}{|c|}{$95 \% \mathrm{Cl}$} & \multirow{2}{*}{$\begin{array}{c}p \\
\text { Value }\end{array}$} & \multirow[b]{2}{*}{$\mathrm{HR}$} & \multicolumn{2}{|c|}{$95 \% \mathrm{Cl}$} & \multirow{2}{*}{$\begin{array}{c}p \\
\text { Value }\end{array}$} \\
\hline & & Upper & Lower & & & Upper & Lower & & & Upper & Lower & \\
\hline \multicolumn{13}{|l|}{ Age } \\
\hline$<7$ yrs & 1 & 1 & 1 & & 1 & 1 & 1 & & 1 & 1 & 1 & \\
\hline $7-12$ yrs & 0.15 & 0.013 & 1.785 & 0.13 & 0.88 & 0.24 & 3.20 & 0.85 & 1.00 & 0.41 & 2.45 & 0.98 \\
\hline$>12$ yrs & 0.11 & 0.010 & 1.325 & 0.08 & 0.74 & 0.21 & 2.55 & 0.63 & 1.29 & 0.54 & 3.09 & 0.55 \\
\hline \multicolumn{13}{|l|}{ Sex } \\
\hline Male & 1.00 & 1.00 & 1.00 & & 1.00 & 1.00 & 1.00 & & 1.00 & 1.00 & 1.00 & \\
\hline Female & 0.68 & 0.25 & 1.83 & 0.44 & 0.52 & 0.25 & 1.07 & 0.07 & 0.86 & 0.47 & 1.59 & 0.64 \\
\hline \multicolumn{13}{|l|}{ Tumor location } \\
\hline Cervical & 1.00 & 1.00 & 1.00 & & 1.00 & 1.00 & 1.00 & & 1.00 & 1.00 & 1.00 & \\
\hline Cervicothoracic & 0.35 & 0.07 & 1.67 & 0.19 & 0.30 & 0.09 & 0.99 & 0.048 & 0.37 & 0.15 & 0.91 & 0.03 \\
\hline Thoracic & 2.39 & 0.47 & 12.17 & 0.29 & 0.29 & 0.10 & 0.78 & 0.014 & 0.58 & 0.27 & 1.23 & 0.157 \\
\hline Conus & 0.44 & 0.12 & 1.63 & 0.22 & 0.31 & 0.12 & 0.81 & 0.017 & 0.56 & 0.25 & 1.24 & 0.154 \\
\hline Others & NR & NR & NR & NR & & & & & & & & \\
\hline \multicolumn{13}{|l|}{ Surgical intervention } \\
\hline Biopsy & 1.00 & 1.00 & 1.00 & & 1.00 & 1.00 & 1.00 & & 1.00 & 1.00 & 1.00 & \\
\hline STR & 0.66 & 0.08 & 5.48 & 0.70 & 3.29 & 0.75 & 14.44 & 0.11 & 1.44 & 0.58 & 3.56 & 0.42 \\
\hline GTR & 0.27 & 0.01 & 4.75 & 0.37 & 2.76 & 0.37 & 20.66 & 0.32 & .76 & 0.24 & 2.41 & 0.65 \\
\hline NOS & 0.33 & 0.03 & 3.51 & 0.35 & 2.77 & 0.54 & 14.21 & 0.22 & 1.57 & 0.52 & 4.72 & 0.42 \\
\hline \multicolumn{13}{|l|}{ Treatment type } \\
\hline Surgery & 1.00 & 1.00 & 1.00 & & 1.00 & 1.00 & 1.00 & & 1.00 & 1.00 & 1.00 & \\
\hline Surgery+RT & 0.44 & 0.15 & 1.31 & 0.14 & 0.86 & 0.34 & 2.22 & 0.77 & 0.92 & 0.37 & 2.24 & 0.85 \\
\hline Surgery+CT & NR & NR & NR & NR & 0.51 & 0.10 & 2.45 & 0.40 & 0.95 & 0.22 & 4.52 & 0.94 \\
\hline Surgery+RT+CT & 0.40 & 0.09 & 1.66 & 0.21 & 0.42 & 0.17 & 1.03 & 0.06 & 0.48 & 0.20 & 1.06 & 0.07 \\
\hline
\end{tabular}

0.04, log-rank test). The median survival of patients with intracranial GBM is $13-43$ months..$^{35,40,53,57}$ In the present study of spinal GBM, we found a median OS of 10 months. The 6-, 12-, and 18-month survival rates for primary spinal GBM were $67 \%, 35 \%$, and $9 \%$, respectively.

Lam et al. ${ }^{23}$ analyzed the Surveillance Epidemiology and End Results (SEER) data in the pediatric population. They found that the median survival in spinal GBM was 7 months and that the addition of RT does not prolong OS. Ononiwu et al. ${ }^{38}$ and O'Sullivan et al. ${ }^{37}$ demonstrated that the addition of RT after surgery could prolong OS. In infants and young patients ( $<3$ years of age), however, adjuvant therapy is reserved for recurrent malignant spinal cord tumors. ${ }^{11}$ In contrast, according to 2 other reports, median OS for the child with intracranial GBM was 13.5 months ${ }^{35}$ and 16 months. ${ }^{3}$ The Children's Cancer Study Group (CCG)-943 results revealed that CT combined with RT had a significant role in intracranial GBM $(\mathrm{p}=0.026){ }^{16}$ Another study ${ }^{50}$ revealed that the 5-year event-free survival was $42 \%$ with combination therapy as compared to $6 \%$ with radiation alone $(p=0.01)$. The role of preoperative or postoperative CT in pediatric high-grade glioma (HGG) is still debatable. Merchant et al. ${ }^{29}$ opined that preoperative
CT is beneficial because of the undisturbed microvasculature of the tumor. However, Massimo et al. ${ }^{26}$ recommended postoperative CT in view of the damaged blood-brain barrier. In the present systematic analysis, we found that a child treated with surgery alone had a worse OS than those treated with surgery plus adjuvant therapy $(\mathrm{p}=0.01, \log$ rank test). A child who received RT or CT after surgery had an OS of 6 and 10 months, respectively. The OS of a child who received combination therapy consisting of surgery, RT, and CT was 11 months.

Reportedly, leptomeningeal spread is more frequent in spinal GBM (39\%) than its intracranial counterpart (27\%), and it also limits final survival.,952 However, our study did not provide evidence supporting the assertion that leptomeningeal spread limits final survival. We found CSF dissemination in $42 \%$ of cases with a median survival of 10 months. However, children who developed hydrocephalus $(13.2 \%)$ with spinal GBM had a shorter average survival of 8 months.

Various genetic studies have demonstrated that EGFR amplification, PTEN mutations, p16 and p27 expression, and $I D H$ alterations have a lower frequency and that PDGFR, loss of heterozygosity on $19 \mathrm{q}$ and $22 \mathrm{q}$, and P53 
TABLE 4. Cox multivariate analysis of OS

\begin{tabular}{|c|c|c|c|}
\hline Variable & $\mathrm{HR}$ & $95 \% \mathrm{Cl}$ & $p$ Value \\
\hline \multicolumn{4}{|l|}{ Age } \\
\hline$<7$ yrs & 1 & 1 & 1 \\
\hline $7-12$ yrs & 2.31 & $0.81-6.61$ & 0.11 \\
\hline$>12$ yrs & 2.32 & $0.80-6.72$ & 0.12 \\
\hline \multicolumn{4}{|l|}{ Sex } \\
\hline Male & 1 & 1 & 1 \\
\hline Female & 0.91 & $0.44-1.88$ & 0.81 \\
\hline \multicolumn{4}{|l|}{ Location } \\
\hline Cervical & 1 & 1 & 1 \\
\hline Cervicothoracic & 0.24 & $0.09-0.62$ & 0.004 \\
\hline Thoracic & 0.27 & $0.10-0.72$ & 0.009 \\
\hline Conus & 0.19 & $0.06-0.56$ & 0.003 \\
\hline Others & 0.05 & $0.003-0.81$ & 0.09 \\
\hline \multicolumn{4}{|l|}{ Surgery type } \\
\hline Biopsy & 1 & 1 & 1 \\
\hline STR & 0.99 & $0.037-2.64$ & 0.99 \\
\hline GTR & 0.23 & $0.07-0.77$ & 0.01 \\
\hline NOS & 0.42 & $0.098-1.79$ & 0.24 \\
\hline \multicolumn{4}{|l|}{ Treatment type } \\
\hline Surgery only & 1 & 1 & 1 \\
\hline Surgery+RT & 0.64 & $0.21-1.92$ & 0.43 \\
\hline Surgery+CT & 0.45 & $0.08-2.43$ & 0.35 \\
\hline Surgery+RT+CT & 0.37 & $0.11-1.27$ & 0.116 \\
\hline
\end{tabular}

Boldface type indicates significance.

have overexpression in pediatric HGG. ${ }^{39,41,55}$ In pediatric GBM, Nakamura et al. ${ }^{33}$ reported that the high frequency of p53 mutations and loss of heterozygosity on $19 q$ and $22 q$ in children 6 years or older, in comparison with a younger age, influences OS. The DNA methylation of GBM has

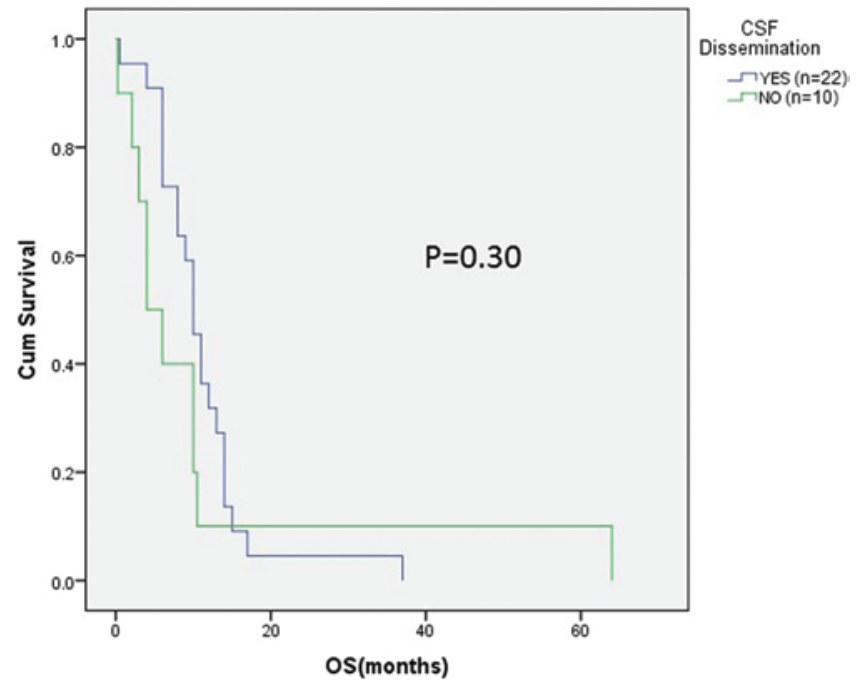

FIG. 4. Comparison of OS based on CSF dissemination in children with primary spinal GBM. A $p<0.05$ was considered statistically significant. Figure is available in color online only.

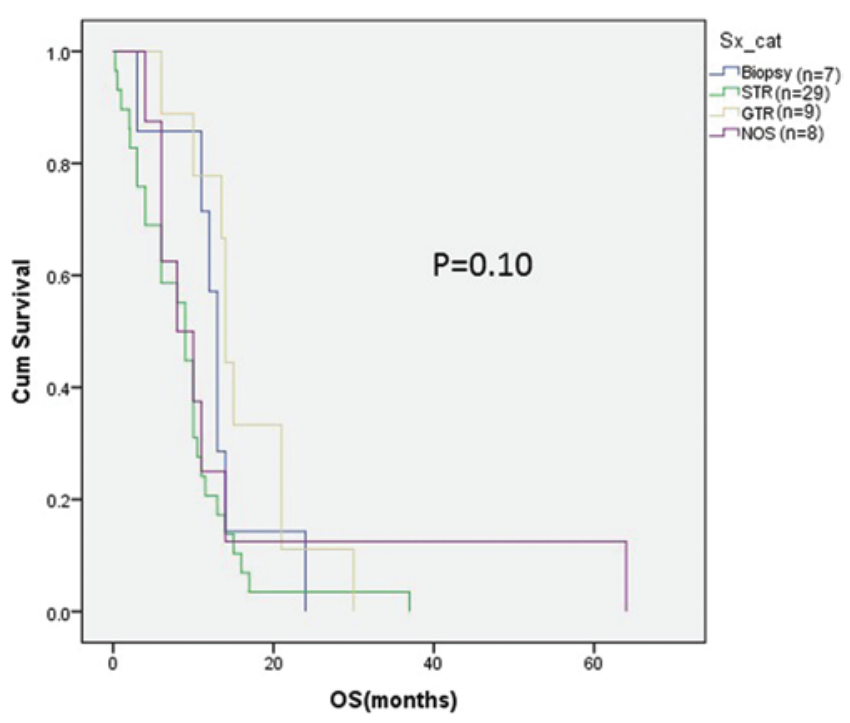

FIG. 5. Comparison of OS based on surgery (Sx) category. A $p<0.05$ was considered statistically significant. Figure is available in color online only.

been established as a biomarker for anticipating the gain of temozolomide CT, especially in elderly GBM patients. Meanwhile, both the frequency $(16 \%-50 \%)$ and the prognostic importance of $\mathrm{O}^{6}$-methylguanine-DNA-methyltransferase (MGMT) silencing in pediatric HGG remain controversial..$^{33}$ The molecular target for pediatric GBM is vascular endothelial growth factor (VEGF). However, the beneficial results of adding bevacizumab to the treatment protocol for intracranial GBM are debatable. ${ }^{34}$ Other factors-for example, fibroblast growth factor (FGF), epidermal growth factor receptor (EGFR), and platelet-derived growth factor (PDGF)-are under investigation in the management of pediatric malignant tumors. ${ }^{14}$ The introduction of Nimotuzumab (humanized IgG1 monoclonal

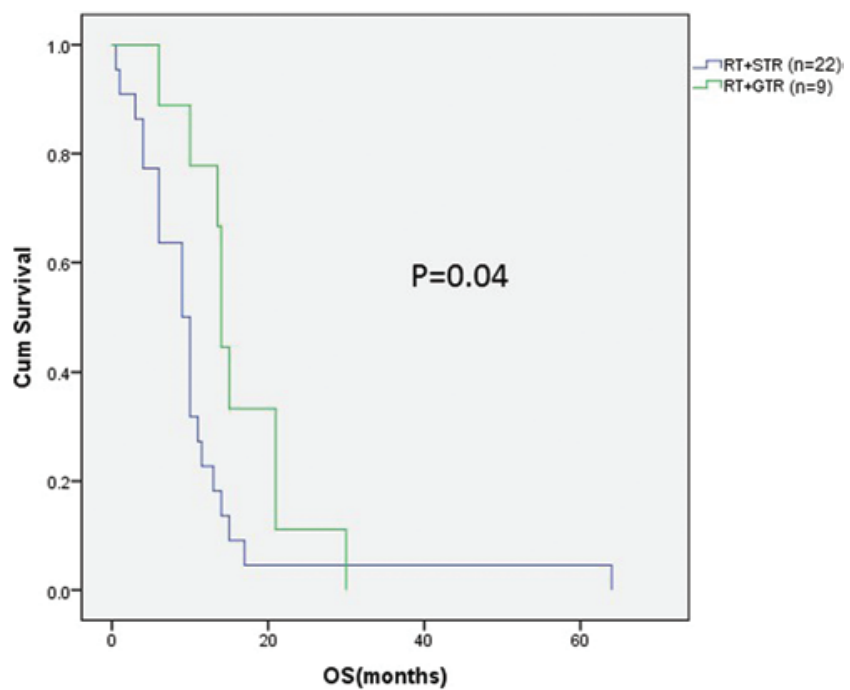

FIG. 6. Comparison of OS between GTR and RT versus STR and RT. A $p<0.05$ was considered statistically significant. Figure is available in color online only. 


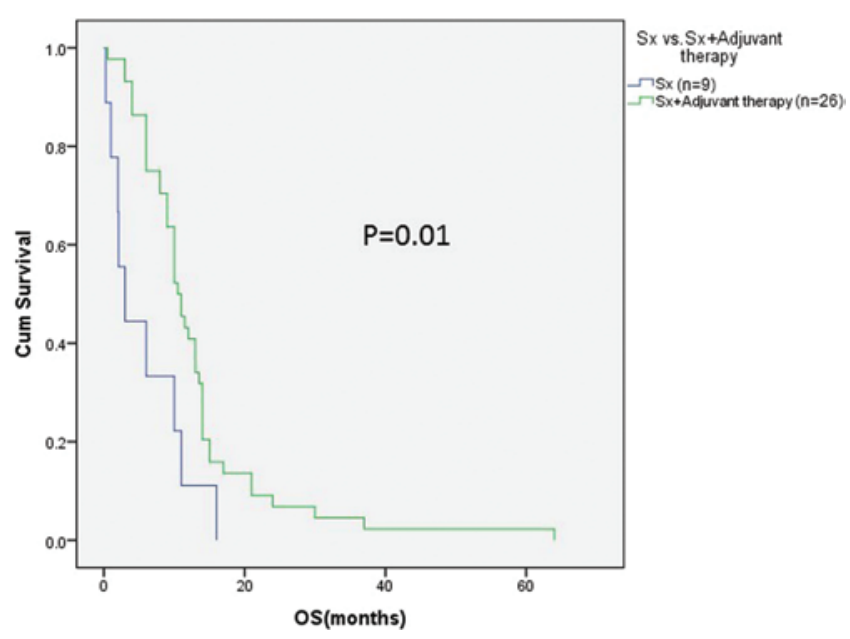

FIG. 7. Comparison of OS between surgery alone versus surgery with adjuvant therapy in children with GBM. A p $<0.05$ was considered statistically significant. Figure is available in color online only.

antibody), either alone or with RT and CT, is the latest achievement. ${ }^{6}$ It works against EGFR and has shown OS of 32.66 months and a 2-year survival rate of $54.2 \%$ in pediatric intracranial HGG. The pending administration of the histone deacetylase (HDAC) inhibitor ${ }^{6}$ vorinostat in the treatment of recurrent GBM may be a new direction even in spinal GBM. Faury et al. ${ }^{15}$ compared pediatric and adult GBM samples for activation of Ras and Akt pathways and revealed a subset of pediatric GBMs with activation of the pathways, a neural stem cell phenotype, and a very poor prognosis. This pediatric GBM subset was distinct from the adult subset and showed nuclear overexpression of Y-box binding protein 1 (YB-1). However, as spinal GBM is a rare tumor in the pediatric population, it would be difficult to find out the predictors from molecular data unless more cases are reported in the future. Therefore, we need a large-scale prospective study addressing all of these molecular factors to assess their impact on OS in spinal GBM in the pediatric population.

\section{Study Limitations}

Our analysis was primarily based on case reports and small case series because of the very low incidence of primary spinal GBM. Therefore, the inherent bias of treatment selection could not be avoided. Neither does our study include radiological findings such as the presence of a cyst or information regarding radiation dosage. Given the scarcity of information regarding type, duration, and doses of CT, we were unable to include that information in the final analysis. The pooled data may not be an accurate reflection of all pediatric spinal GBM as only articles published in English were included in the study. Moreover, the contradictory results in the univariate and multivariate analyses is possibly attributable to 1) the effect of unequal sample sizes, 2) the impact of missing data, and 3) the presence of interaction with other variables. ${ }^{24}$ The major strength of our study is that it consists of the largest number of cases of primary GBM of the spinal cord in the pediatric age group.

\section{Conclusions}

Determining the optimal management protocol for primary spinal GBM in the pediatric age group is difficult given the rarity of cases. The mainstay of treatment for spinal GBM remains surgery followed by adjuvant therapy. Results of the present study favored RT after GTR of the tumor. Older age, cervical location, and surgery alone are the factors predictive of poor OS.

\section{References}

1. Adams H, Adams HH, Jackson C, Rincon-Torroella J, Jallo GI, Quiñones-Hinojosa A: Evaluating extent of resection in pediatric glioblastoma: a multiple propensity score-adjusted population-based analysis. Childs Nerv Syst 32:493-503, 2016

2. Allen JC, Aviner S, Yates AJ, Boyett JM, Cherlow JM, Turski PA, et al: Treatment of high-grade spinal cord astrocytoma of childhood with " 8 -in-1" chemotherapy and radiotherapy: a pilot study of CCG-945. J Neurosurg 88:215-220, 1998

3. Ansari M, Nasrolahi H, Kani AA, Mohammadianpanah M, Ahmadloo N, Omidvari S, et al: Pediatric glioblastoma multiforme: a single-institution experience. Indian J Med Paediatr Oncol 33:155-160, 2012

4. Banczerowski P, Simó M, Sipos L, Slowik F, Benoist G, Veres R: Primary intramedullary glioblastoma multiforme of the spinal cord: report of eight cases. Ideggyogy Sz 56:2832, 2003

5. Bonde V, Balasubramaniam S, Goel A: Glioblastoma multiforme of the conus medullaris with holocordal spread. J Clin Neurosci 15:601-603, 2008

6. Cabanas R, Saurez G, Rios M, Alert J, Reyes A, Valdes J, et al: Treatment of children with high grade glioma with nimotuzumab: a 5-year institutional experience. MAbs 5:202-207, 2013

7. Campbell JW, Pollack IF, Martinez AJ, Shultz B: Highgrade astrocytomas in children: radiologically complete resection is associated with an excellent long-term prognosis. Neurosurgery 38:258-264, 1996

8. Caroli E, Salvati M, Ferrante L: Spinal glioblastoma with brain relapse in a child: clinical considerations. Spinal Cord 43:565-567, 2005

9. Ciappetta P, Salvati M, Capoccia G, Artico M, Raco A, Fortuna A: Spinal glioblastomas: report of seven cases and review of the literature. Neurosurgery 28:302-306, 1991

10. Cohen AR, Wisoff JH, Allen JC, Epstein F: Malignant astrocytomas of the spinal cord. J Neurosurg 70:50-54, 1989

11. Constantini S, Houten J, Miller DC, Freed D, Ozek MM, Rorke LB, et al: Intramedullary spinal cord tumors in children under the age of 3 years. J Neurosurg 85:10361043, 1996

12. Das KK, Mehrotra A, Nair AP, Kumar S, Srivastava AK, Sahu RN, et al: Pediatric glioblastoma: clinico-radiological profile and factors affecting the outcome. Childs Nerv Syst 28:2055-2062, 2012

13. Derinkuyu BE, Boyunaga O, Okur A, Alimli AG, Oztunali C, Damar C, et al: Primary intraspinal glioblastoma multiforme in a child. Spine J 15:e37-e38, 2015

14. Ellis LM, Hicklin DJ: Pathways mediating resistance to vascular endothelial growth factor-targeted therapy. Clin Cancer Res 14:6371-6375, 2008

15. Faury D, Nantel A, Dunn SE, Guiot MC, Haque T, Hauser P, et al: Molecular profiling identifies prognostic subgroups of pediatric glioblastoma and shows increased YB-1 expression in tumors. J Clin Oncol 25:1196-1208, 2007

16. Finlay JL, Boyett JM, Yates AJ, Wisoff JH, Milstein JM, Geyer JR, et al: Randomized phase III trial in childhood high-grade astrocytoma comparing vincristine, lomustine, 
and prednisone with the eight-drugs-in-1-day regimen. J Clin Oncol 13:112-123, 1995

17. Gee TS, Ghani AR, Idris B, Awang MS: Case report: a rare case of pediatric conus medularis glioblastoma multiforme. Med J Malaysia 67:438-441, 2012

18. Johnson DL, Schwarz S: Intracranial metastases from malignant spinal-cord astrocytoma. Case report. J Neurosurg 66:621-625, 1987

19. Kawashima A, Sasajima T, Sugawara T, Takahashi M, Suzuki A, Higashiyama N, et al: [Unusual MR appearance of intracranial dissemination from cervical glioblastoma.] No Shinkei Geka 32:937-944, 2004 (Jpn)

20. Kim WH, Yoon SH, Kim CY, Kim KJ, Lee MM, Choe G, et al: Temozolomide for malignant primary spinal cord glioma: an experience of six cases and a literature review. J Neurooncol 101:247-254, 2011 (Erratum in J Neurooncol 101:255, 2011)

21. Klepstad P, Borchgrevink P, Hval B, Flaat S, Kaasa S: Longterm treatment with ketamine in a 12-year-old girl with severe neuropathic pain caused by a cervical spinal tumor. J Pediatr Hematol Oncol 23:616-619, 2001

22. Kramm CM, Wagner S, Van Gool S, Schmid H, Sträter $\mathrm{R}$, Gnekow A, et al: Improved survival after gross total resection of malignant gliomas in pediatric patients from the HIT-GBM studies. Anticancer Res 26 (5B):3773-3779, 2006

23. Lam S, Lin Y, Melkonian S: Analysis of risk factors and survival in pediatric high-grade spinal cord astrocytoma: a population-based study. Pediatr Neurosurg 48:299-305, 2012

24. Lo SK, Li IT, Tsou TS, See L: [Non-significant in univariate but significant in multivariate analysis: a discussion with examples.] Changgeng Yi Xue Za Zhi 18:95-101, 1995 (Chinese)

25. Lober R, Sharma S, Bell B, Free A, Figueroa R, Sheils $\mathrm{CW}$, et al: Pediatric primary intramedullary spinal cord glioblastoma. Rare Tumors 2:e48, 2010

26. Massimino M, Gandola L, Luksch R, Spreafico F, Riva D, Solero C, et al: Sequential chemotherapy, high-dose thiotepa, circulating progenitor cell rescue, and radiotherapy for childhood high-grade glioma. Neuro Oncol 7:41-48, 2005

27. McGirt MJ, Goldstein IM, Chaichana KL, Tobias ME, Kothbauer KF, Jallo GI: Extent of surgical resection of malignant astrocytomas of the spinal cord: outcome analysis of 35 patients. Neurosurgery 63:55-61, 2008

28. Medhkour A, Chan M: Extremely rare glioblastoma multiforme of the conus medullaris with holocord and brain stem metastases, leading to cranial nerve deficit and respiratory failure: a case report and review of the literature. Surg Neurol 63:576-583, 2005

29. Merchant TE, Nguyen D, Thompson SJ, Reardon DA, Kun LE, Sanford RA: High-grade pediatric spinal cord tumors. Pediatr Neurosurg 30:1-5, 1999

30. Minehan KJ, Brown PD, Scheithauer BW, Krauss WE, Wright MP: Prognosis and treatment of spinal cord astrocytoma. Int J Radiat Oncol Biol Phys 73:727-733, 2009

31. Mori K, Imai S, Shimizu J, Taga T, Ishida M, Matsusue Y: Spinal glioblastoma multiforme of the conus medullaris with holocordal and intracranial spread in a child: a case report and review of the literature. Spine J 12:e1-e6, 2012

32. Mortara R, Parker JC Jr, Brooks WH: Glioblastoma multiforme of the spinal cord. Surg Neurol 2:115-119, 1974

33. Nakamura M, Shimada K, Ishida E, Higuchi T, Nakase $\mathrm{H}$, Sakaki T, et al: Molecular pathogenesis of pediatric astrocytic tumors. Neuro Oncol 9:113-123, 2007

34. Narayana A, Kunnakkat S, Chacko-Mathew J, Gardner S, Karajannis M, Raza S, et al: Bevacizumab in recurrent highgrade pediatric gliomas. Neuro Oncol 12:985-990, 2010

35. Nikitovic M, Stanic D, Pekmezovic T, Gazibara MS, Bokun J,
Paripovic L, et al: Pediatric glioblastoma: a single institution experience. Childs Nerv Syst 32:97-103, 2016

36. O'Halloran PJ, Farrell M, Caird J, Capra M, O'Brien D: Paediatric spinal glioblastoma: case report and review of therapeutic strategies. Childs Nerv Syst 29:367-374, 2013

37. O'Sullivan C, Jenkin RD, Doherty MA, Hoffman HJ, Greenberg ML: Spinal cord tumors in children: long-term results of combined surgical and radiation treatment. J Neurosurg 81:507-512, 1994

38. Ononiwu C, Mehta V, Bettegowda C, Jallo G: Pediatric spinal glioblastoma multiforme: current treatment strategies and possible predictors of survival. Childs Nerv Syst 28:715-720, 2012

39. Parsons DW, Jones S, Zhang X, Lin JC, Leary RJ, Angenendt $\mathrm{P}$, et al: An integrated genomic analysis of human glioblastoma multiforme. Science 321:1807-1812, 2008

40. Perkins SM, Rubin JB, Leonard JR, Smyth MD, El Naqa I, Michalski JM, et al: Glioblastoma in children: a singleinstitution experience. Int J Radiat Oncol Biol Phys 80:1117-1121, 2011

41. Pollack IF, Hamilton RL, James CD, Finkelstein SD, Burnham J, Yates AJ, et al: Rarity of PTEN deletions and EGFR amplification in malignant gliomas of childhood: results from the Children's Cancer Group 945 cohort. J Neurosurg 105 (5 Suppl):418-424, 2006

42. Prasad GL, Borkar SA, Subbarao KC, Suri V, Mahapatra AK: Primary spinal cord glioblastoma multiforme: a report of two cases. Neurol India 60:333-335, 2012

43. Przybylski GJ, Albright AL, Martinez AJ: Spinal cord astrocytomas: long-term results comparing treatments in children. Childs Nerv Syst 13:375-382, 1997

44. Raco A, Esposito V, Lenzi J, Piccirilli M, Delfini R, Cantore G: Long-term follow-up of intramedullary spinal cord tumors: a series of 202 cases. Neurosurgery 56:972-981, 2005

45. Raco A, Piccirilli M, Landi A, Lenzi J, Delfini R, Cantore G: High-grade intramedullary astrocytomas: 30 years' experience at the Neurosurgery Department of the University of Rome "Sapienza". J Neurosurg Spine 12:144-153, 2010

46. Russell DS, Rubinstein LJ: Pathology of Tumors of the Nervous System. London: Edward Arnold \& Co, 1959

47. Sánchez-Herrera F, Castro-Sierra E, Gordillo-Domínguez LF, Vaca-Ruiz MA, Santana-Montero B, Perezpeña-Diazconti $\mathrm{M}$, et al: Glioblastoma multiforme in children: experience at Hospital Infantil de Mexico Federico Gomez. Childs Nerv Syst 25:551-557, 2009

48. Santi M, Mena H, Wong K, Koeller K, Olsen C, Rushing EJ: Spinal cord malignant astrocytomas. Clinicopathologic features in 36 cases. Cancer 98:554-561, 2003

49. Sharma S, Free A, Mei Y, Peiper SC, Wang Z, Cowell JK: Distinct molecular signatures in pediatric infratentorial glioblastomas defined by aCGH. Exp Mol Pathol 89:169_ 174,2010

50. Sposto R, Ertel IJ, Jenkin RD, Boesel CP, Venes JL, Ortega JA, et al: The effectiveness of chemotherapy for treatment of high grade astrocytoma in children: results of a randomized trial. A report from the Childrens Cancer Study Group. J Neurooncol 7:165-177, 1989

51. Stecco A, Quirico C, Giampietro A, Sessa G, Boldorini R, Carriero A: Glioblastoma multiforme of the conus medullaris in a child: description of a case and literature review. AJNR Am J Neuroradiol 26:2157-2160, 2005

52. Strik HM, Effenberger O, Schäfer O, Risch U, Wickboldt J, Meyermann R: A case of spinal glioblastoma multiforme: immunohistochemical study and review of the literature. J Neurooncol 50:239-243, 2000

53. Sturm D, Bender S, Jones DT, Lichter P, Grill J, Becher O, et al: Paediatric and adult glioblastoma: multiform (epi)genomic culprits emerge. Nat Rev Cancer 14:92-107, 2014 
54. Sun J, Wang Z, Li Z, Liu B: Microsurgical treatment and functional outcomes of multi-segment intramedullary spinal cord tumors. J Clin Neurosci 16:666-671, 2009

55. Suri V, Das P, Pathak P, Jain A, Sharma MC, Borkar SA, et al: Pediatric glioblastomas: a histopathological and molecular genetic study. Neuro Oncol 11:274-280, 2009 (Erratum in Neuro Oncol 11:972, 2009)

56. Tashiro K, Tachibana S, Tsura M: [Clinicopathological studies of spinal cord neoplasm with disseminating intracranial metastasis possibly producing akinetics mutism.] No To Shinkei 28:1311-1318, 1976 (Jpn)

57. Vanan MI, Eisenstat DD: Management of high-grade gliomas in the pediatric patient: Past, present, and future. Neurooncol Pract 1:145-157, 2014

58. Wisoff JH, Boyett JM, Berger MS, Brant C, Li H, Yates AJ, et al: Current neurosurgical management and the impact of the extent of resection in the treatment of malignant gliomas of childhood: a report of the Children's Cancer Group trial no. CCG-945. J Neurosurg 89:52-59, 1998

59. Wolff B, Ng A, Roth D, Parthey K, Warmuth-Metz M, Eyrich M, et al: Pediatric high grade glioma of the spinal cord: results of the HIT-GBM database. J Neurooncol 107:139146,2012

60. Yasui T, Hakuba A, Katsuyama J, Nishimura S:
Microsurgical removal of intramedullary spinal cord tumours: report of 22 cases. Acta Neurochir Suppl 43:9-12, 1988

\section{Disclosures}

The authors report no conflict of interest concerning the materials or methods used in this study or the findings specified in this paper.

\section{Author Contributions}

Conception and design: Konar. Acquisition of data: Konar. Analysis and interpretation of data: Konar, Bir, Maiti. Drafting the article: Konar. Critically revising the article: all authors. Reviewed submitted version of manuscript: Nanda. Approved the final version of the manuscript on behalf of all authors: Nanda. Statistical analysis: Konar, Bir, Maiti. Study supervision: Nanda.

\section{Correspondence}

Anil Nanda, Department of Neurosurgery, LSU Health Shreveport, 1501 Kings Hwy., Shreveport, LA 71130-3932. email: ananda@1suhsc.edu. 